\title{
Rastreio pré-natal de cromossomopatias e defeitos do tubo neural. Como actuar?
}

Sílvia Henriques*

\section{RESUMO}

Objectivos: O rastreio pré-natal (RPN) permite determinar, de modo não invasivo, o risco de trissomia 21, trissomia 18 e defeitos do tubo neural (DTN). No entanto, persistem dúvidas sobre a sua correcta aplicação a que esta revisão procura dar resposta: dever-se-á propor o RPN a todas as grávidas? Qual o método de rastreio mais adequado?

Fontes de Dados: Medline, Tripdatabase, Cochrane, National Guideline Clearinghouse, CMAinfobase, NeLH guidelines finder, UPToDate, IndexRMP.

Métodos de Revisão: Pesquisa sistemática de artigos publicados entre 01-01-1999 e 25-08-2007 em inglês, português e espanhol, com as palavras-chave «prenatal diagnosis» e "Down syndrome», e no site IndexRMP com «rastreio pré-natal». Foram seleccionados 2 guidelines (recomendações), 1 guideline baseada na evidência (MBE), 2 revisões MBE, 3 revisões sistemáticas e 9 estudos prospectivos. Os resultados foram classificados por níveis de evidência segundo a taxonomia da American Family Physician.

População: Mulheres com gravidezes espontâneas unifetais

Resultados: O RPN deve ser proposto a todas as grávidas que iniciem a rotina pré-natal antes das 20 semanas de gestação, independentemente da idade, com consentimento informado [B]. O DPN deverá ser igualmente proposto, com informação adequada [C]. A idade materna não deverá ser utilizada como limite para propor o RPN ou o DPN [C].

Antes das 14 semanas completas de gestação, o método mais eficaz e com menos falsos-positivos é o rastreio integrado completo; quando não é possível medir a translucência da nuca: rastreio integrado simples. Se a grávida quiser saber os resultados precocemente: rastreios sequenciais passo-a-passo ou contingente ou rastreio do $1^{\circ}$ trimestre combinado (neste caso é aconselhável o rastreio de DTN no $2^{\circ}$ trimestre através da quantificação de alfa-fetoproteína ou ecografia). Após as 14 semanas: rastreio quádruplo do $2^{\circ}$ trimestre. O rastreio sequencial independente é desaconselhado. [C]

Conclusões: Perante a evidência disponível e as questões éticas que o RPN levanta, o médico deve ajudar os casais a tomar uma decisão esclarecida, fornecendo informação objectiva e isenta e escolhendo as alternativas mais eficazes e seguras, caso a caso.

Palavras-chave: Rastreio Pré-natal; Síndrome de Down; Trissomia 21; Trissomia 18; Defeitos do Tubo Neural.

\section{INTRODUÇÃO}

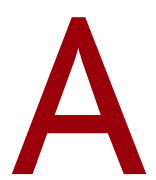

o longo das últimas décadas têm-se verificado avanços consideráveis no diagnóstico pré-natal de cromossomopatias (DPN). Por consenso, os testes de DPN existentes - amniocentese, biopsia das vilosidades coriónicas, cordocentese - têm sido oferecidos às mulheres com idade igual ou superior a 35 anos na data do parto. Outro critério tradicionalmente utilizado para oferecer o DPN é o risco aumentado de aneuploidia fetal, que se baseia na existência de aneuploidias cromossómicas em gravidezes anteriores, defeitos estruturais major do feto detectados por ecografia na gestação actual, e alterações cromossómicas numéricas ou estruturais dos progenitores. ${ }^{1}$

As Orientações Técnicas no 2 da Direcção-Geral da Saúde (Vigilância pré-natal e revisão do puerpério) vão 
no mesmo sentido: «A grávidas de 35 anos ou mais, pedir amniocentese, a realizar às 12-16 semanas, para diagnóstico pré-natal». ${ }^{2} \mathrm{O}$ que justifica o critério da idade materna é o facto de, aos 35 anos, a incidência de gravidezes com trissomias aumentar significativamente ${ }^{3} \mathrm{e}$ o risco de Síndrome de Down (SD) igualar o risco de perda fetal relacionada com os testes de DPN. ${ }^{4}$

A amniocentese é, de longe, o método de DPN mais utilizado em Portugal. Sendo uma técnica invasiva, comporta um risco de $1 \%$ de aborto iatrogénico ${ }^{5}$ e custos consideráveis.

Os critérios acima referidos para realização de DPN têm sido alvo de discussão. ${ }^{6} \mathrm{~A}$ utilização da idade materna como critério único para recorrer ao DPN é insuficiente pois não contempla os $50 \%$ de gravidezes com SD que ocorrem antes dos 35 anos. ${ }^{7}$ Mesmo o critério «risco aumentado de aneuploidia fetal» é discutível uma vez que, de entre as gravidezes com SD, $97 \%$ ocorrem em famílias sem história prévia do síndrome, e mais de $95 \%$ de todos os defeitos abertos do tubo neural (DTN) ocorrem em mulheres grávidas sem factores de risco conhecidos, por exemplo um DTN num familiar próximo ou numa gravidez anterior. ${ }^{8}$

O recurso ao rastreio pré-natal de cromossomopatias e defeitos do tubo neural (RPN) evoluiu rapidamente a partir de 1984, quando Merkatz e seus colaboradores encontraram uma associação estatisticamente significativa entre níveis baixos de alfa-fetoproteína (AFP) e cariótipo anormal do feto. ${ }^{9}$ A partir dessa altura foram identificados marcadores adicionais (ß-hCG-gonadotrofina coriónica humana; PAPP-A - proteína A plasmática associada à gravidez; $\mu \mathrm{E} 3$ - estriol não conjugado; inibina A) e criados programas de rastreio com diferentes métodos para identificação do risco de DTN, SD e outras anomalias fetais como a trissomia 18.

Durante a década de 1990 estabeleceu-se uma forte associação entre uma translucência da nuca (TN) elevada e o SD. ${ }^{10} \mathrm{ATN}$ é uma imagem ecográfica hipo-ecogénica que traduz uma acumulação de líquido na região cervical posterior do feto, devendo ser medida entre as $11 \mathrm{e}$ as 13+6 semanas. Considera-se elevada uma TN que ultrapasse o percentil 95 para a idade gestacional, o que equivale a um valor superior a $3 \mathrm{~mm} \cdot{ }^{11} \mathrm{~A}$ medição correcta da TN exige treino especializado e garantia contínua da qualidade. A Fetal Medicine Foundation (Reino Unido) desenvolveu recomendações para a correcta medição da TN de forma a maximizar a sua reprodutibilidade e precisão. ${ }^{12}$ Além disso, introduziu um programa de treino para a realização do exame ultrassonográfico no primeiro trimestre com emissão do respectivo certificado, de forma a facilitar o estabelecimento de um alto padrão nessa prática, de âmbito internacional.

Recentemente foi observado que, numa elevada percentagem de casos de SD, os ossos do nariz do feto no final do $1^{\circ}$ trimestre não são visualizáveis. ${ }^{13}$ Esta característica já constitui, em alguns centros, um marcador ecográfico adicional para SD, mas o seu valor para fins de rastreio na população geral é ainda controverso. ${ }^{14}$

Actualmente estão disponíveis vários métodos de rastreio pré-natal que, utilizando marcadores bioquímicos e ecográficos, permitem identificar, de modo não invasivo, as gravidezes com risco aumentado de SD, síndrome de Edwards (trissomia 18) e DTN. O Quadro I resume as principais características dos métodos mais utilizados e descritos na literatura.

Os métodos de rastreio do $1^{\circ}$ trimestre devem ser realizados entre a $10^{\mathrm{a}}$ e a $13^{\mathrm{a}}$ semanas de gestação (idealmente às 11 semanas). $O$ rastreio do $1^{\circ}$ trimestre isolado baseia-se na determinação sérica da PAPP-A e da ß-hCG livre. O rastreio do $1^{\circ}$ trimestre combinado inclui também uma ecografia obstétrica (idealmente às 11 semanas) para a medição da translucência da nuca.

A realização isolada da ecografia com medição da TN é também considerada um método válido de RPN, sendo que a sua taxa de detecção é substancialmente mais elevada do que cada um dos marcadores séricos diponíveis. No entanto, esta aumenta significativamente se se combinarem os achados ecográficos com os valores analíticos.

Os métodos de rastreio do $2^{\circ}$ trimestre devem ser realizados entre a $14^{\mathrm{a}}$ e a $22^{\mathrm{a}}$ semanas de gestação (idealmente às 15 semanas). O rastreio quádruplo do $2^{\circ}$ trimestre baseia-se na medição dos valores séricos da AFP, $ß$-hCG livre, $\mu E 3$ e Inibina A. Note-se que apenas os métodos de rastreio que incluem a medição da AFP no $2^{\circ}$ trimestre permitem a determinação do risco de DTN.

Os métodos de rastreio integrado e sequencial incluem a realização de exames no $1^{\circ}$ trimestre (PAPP-A $+/$ - ecografia com TN) e no $2^{\circ}$ trimestre (AFP, B-hCG livre, $\mu \mathrm{E} 3$ e Inibina $\mathrm{A})$. $\mathrm{O}$ rastreio integrado simples ba- 
seia-se apenas na medição dos marcadores séricos, enquanto que o rastreio integrado completo inclui a ecografia.

Os rastreios integrados pressupõem a não divulgação dos valores dos testes realizados até que se saibam os resultados das análises do $2^{\circ}$ trimestre, o que poderá ser factor de ansiedade para o casal. No entanto, a combinação dos valores do $1^{\circ} \mathrm{e} 2^{\circ}$ trimestres garante que os rastreios integrados apresentem uma maior taxa de detecção e uma menor percentagem de falsos positivos, com a vantagem de evitarem a realização desnecessária de testes invasivos como a amniocentese que comporta um risco de $1 \%$ de abortamento iatrogénico.

Os rastreios sequenciais (independente, passo-a-passo e contingente) foram desenvolvidos mais recentemente, obviando algumas das desvantagens do rastreio integrado. Com estes métodos as doentes são informadas dos resultados do $1^{\circ}$ trimestre assim que estes são realizados. As que tiverem alto risco de desenvolver alguma anomalia podem optar de imediato por um método de DPN. As restantes, dependendo do método adoptado (ver Quadro I), podem fazer os testes do $2^{\circ}$ trimestre beneficiando da maior taxa de detecção devida à conjugação dos valores dos 2 trimestres (a taxa de falsos positivos não é muito superior à do rastreio integrado), ou podem nem ter de fazer os testes do $2^{\circ}$ trimestre. ${ }^{15}$

Uma vez realizado um teste de rastreio, o risco é calculado tendo em conta a idade materna, a idade gestacional, os níveis de marcadores bioquímicos e outros factores que podem afectar os resultados do teste (o peso da grávida, raça, gemelaridade, SD em gravidez anterior, medicação, tabagismo, diabetes mellitus insulino-dependente, fertilização in vitro). ${ }^{16}$

Devido à variabilidade da concentração dos marcadores séricos ao longo da gravidez, o cálculo do risco só pode ser feito com rigor se se conhecer a idade gestacional correcta. Isso passa, idealmente, pela realização de uma ecografia no primeiro trimestre, em vez do cálculo baseado na data da última menstruação. ${ }^{17}$

Uma vez que, entre diferentes laboratórios, existem diferenças na medição dos marcadores bioquímicos, os valores absolutos obtidos não são comparáveis. Por isso, a concentração de cada marcador é expressa em termos de múltiplos da mediana (MoM) para gravidezes não afectadas da mesma idade gestacional. Nas gra- videzes não afectadas, a distribuição dos valores situase à volta de $1 \mathrm{MoM}$, enquanto que nos casos de SD os valores centram-se à volta de $2 \mathrm{MoM} .^{16}$

O risco é calculado separadamente para cada uma das condições (SD, T18, DTN), normalmente com recurso a programas informáticos. Os limites acima dos quais o rastreio é considerado positivo, são normalmente estabelecidos por cada laboratório. Por exemplo, se o limite estabelecido para SD for de 1:250, um valor de 1:100 significa «rastreio positivo» e 1:650 significa «rastreio negativo». O termo rastreio positivo significa, assim, um risco aumentado de SD/T18/DTN.

O limite é calculado tendo por base o risco de aborto iatrogénico com a amiocentese: se o valor for 1:100, o risco de ocorrência de SD é superior ao risco de aborto iatrogénico; passa-se o contrário para o hipotético resultado de 1:650. Nos casos de RPN positivo para SD está indicada a realização de um teste diagnóstico. A biopsia das vilosidades coriónicas é o teste recomendado no $1^{\circ}$ trimestre, a amniocentese no $2^{\circ}$. Em Portugal, conforme já foi referido, o teste mais utilizado é a amniocentese. Quando o RPN é positivo para DTN ou para trissomia 18, a realização de uma ecografia morfológica detalhada poderá ajudar na decisão de proceder ou não a um teste diagnóstico. ${ }^{18}$

A introdução do rastreio pré-natal em Portugal veio causar dúvidas junto dos profissionais de saúde sobre a sua correcta aplicação. Enquanto a nível internacional existem várias recomendações sobre o RPN, a nível nacional não existem recomendações publicadas, a Direcção-Geral da Saúde é omissa relativamente ao assunto, e mesmo a utilização dos diferentes métodos a nível hospitalar difere de centro para centro. Como actuar perante este recurso que está disponível para as mulheres grávidas e que poderá beneficiá-las?

Procedeu-se a uma revisão baseada na evidência com o objectivo de responder a duas questões essenciais para a prática clínica. Em mulheres com gravidezes espontâneas unifetais o rastreio pré-natal de cromossomaopatias e defeitos do tubo neural deverá ser proposto em todos os casos? Qual o método de rastreio mais eficaz e mais seguro?

\section{MÉTODOS}

Foi realizada uma pesquisa sistemática na Medline e em sites baseados na evidência (Tripdatabase, Cochrane, 
QUADRO I. Métodos de rastreio pré-natal

\begin{tabular}{|c|c|c|c|}
\hline & \multicolumn{2}{|c|}{ Estudos a realizar } & \multirow[b]{2}{*}{ Observações } \\
\hline Método de rastreio pré-natal & $\begin{array}{l}1^{\circ} \text { trimestre } \\
10-13 \text { semanas* } \\
\text { (ideal: } 11 \mathrm{~s} \text { ) }\end{array}$ & $\begin{array}{l}2^{\circ} \text { trimestre } \\
\text { 14-22 semanas } \\
\text { (ideal: } 15 s \text { ) }\end{array}$ & \\
\hline $\begin{array}{l}\text { Rastreio do } 1^{\circ} \text { trimestre } \\
\text { isolado }\end{array}$ & $\begin{array}{l}\text { PAPP-A } \\
ß-h C G \text { livre }\end{array}$ & & \\
\hline $\begin{array}{l}\text { Rastreio do } 1^{\circ} \text { trimestre } \\
\text { combinado }\end{array}$ & $\begin{array}{l}\text { PAPP-A } \\
ß-h C G \text { livre } \\
\text { Ecografia obstétrica }\end{array}$ & & $\begin{array}{l}\text { A ecografia obstétrica realizada entre as } 11 \text { e as } 13 \\
\text { semanas permite a confirmação do tempo da } \\
\text { gravidez e a medição da translucência da nuca. }\end{array}$ \\
\hline $\begin{array}{l}\text { Rastreio quádruplo do } \\
2^{\circ} \text { trimestre }\end{array}$ & & $\begin{array}{l}\text { AFP } \\
\beta-h C G \text { livre } \\
\mu \mathrm{E} 3 \\
\text { Inibina-A }\end{array}$ & $\begin{array}{l}\text { Apenas os métodos de rastreio que incluem a } \\
\text { AFP ( } 2 T \text { T) permitem determinar o risco de } \\
\text { defeitos do tubo neural. }\end{array}$ \\
\hline $\begin{array}{l}\text { Rastreio integrado } \\
\text { simples }\end{array}$ & PAPP-A & $\begin{array}{l}\text { AFP } \\
\beta-h C G \text { livre } \\
\mu \mathrm{E} 3 \\
\text { Inibina-A }\end{array}$ & $\begin{array}{l}\text { Todas as mulheres fazem os testes do } 1 \mathrm{~T} \text { e } 2 \mathrm{~T} \text {. } \\
\text { Os resultados são retidos até à conclusão dos } \\
\text { testes do } 2 \mathrm{~T} \text {, altura em que os resultados são } \\
\text { combinados num resultado único. }\end{array}$ \\
\hline $\begin{array}{l}\text { Rastreio integrado } \\
\text { completo }\end{array}$ & $\begin{array}{l}\text { PAPP-A } \\
\text { Ecografia obstétrica }\end{array}$ & $\begin{array}{l}\text { AFP } \\
ß-h C G \text { livre } \\
\mu E 3 \\
\text { Inibina-A }\end{array}$ & $\begin{array}{l}\text { Todas as mulheres fazem os testes do } 1 \mathrm{~T} \text { e } 2 \mathrm{~T} \text {. } \\
\text { Os resultados são retidos até à conclusão dos } \\
\text { testes do } 2 \mathrm{~T} \text {, altura em que os resultados são } \\
\text { combinados num resultado único. }\end{array}$ \\
\hline $\begin{array}{l}\text { Rastreio sequencial } \\
\text { independente } \\
\text { (independent) }\end{array}$ & $\begin{array}{l}\text { PAPP-A } \\
\beta \text {-hCG livre } \\
\text { Ecografia obstétrica }\end{array}$ & $\begin{array}{l}\text { AFP } \\
\beta-h C G \text { livre } \\
\mu E 3 \\
\text { Inibina-A }\end{array}$ & $\begin{array}{l}\text { Todas as mulheres fazem os testes do } 1 \mathrm{~T} \text {, } \\
\text { cujos resultados são revelados de imediato. } \\
\text { Às doentes com risco muito alto de terem um } \\
\text { feto com cromossomopatia é proposto o DPN. As } \\
\text { mulheres sem risco muito alto fazem os testes do } \\
2 \mathrm{~T} \text {. No entanto, o risco do } 2 \mathrm{~T} \text { é calculado sem } \\
\text { ter em conta os resultados do } 1 \mathrm{~T} \text {. }\end{array}$ \\
\hline $\begin{array}{l}\text { Rastreio sequencial } \\
\text { passo-a-passo } \\
\text { (stepwise) }\end{array}$ & $\begin{array}{l}\text { PAPP-A } \\
\beta-h C G \text { livre } \\
\text { Ecografia obstétrica }\end{array}$ & $\begin{array}{l}\text { AFP } \\
ß-h C G \text { livre } \\
\mu \mathrm{E} 3 \\
\text { Inibina-A }\end{array}$ & $\begin{array}{l}\text { Idêntico ao rastreio sequencial independente } \\
\text { mas o cálculo do risco do } 2 \mathrm{~T} \text { leva em conta os } \\
\text { resultados do } 1 \mathrm{~T} \text {. }\end{array}$ \\
\hline $\begin{array}{l}\text { Rastreio sequencial } \\
\text { contingente } \\
\text { (contingent) }\end{array}$ & $\begin{array}{l}\text { PAPP-A } \\
\beta \text {-hCG livre } \\
\text { Ecografia obstétrica }\end{array}$ & $\begin{array}{l}\text { AFP } \\
\beta-h C G \text { livre } \\
\mu E 3 \\
\text { Inibina-A }\end{array}$ & $\begin{array}{l}\text { Todas as mulheres fazem os testes do } 1^{\circ} \mathrm{T} \text { e } \\
\text { são divididas em } 3 \text { grupos de risco consoante } \\
\text { os resultados: as de baixo risco não fazem } \\
\text { mais testes; às de alto risco é proposto o DPN; as de } \\
\text { médio risco fazem os testes do } 2^{\circ} \mathrm{T} \text { e os resultados } \\
\text { são integrados com os do } 1^{\circ} \mathrm{T} \text {. }\end{array}$ \\
\hline
\end{tabular}

National Guideline Clearinghouse, CMAinfobase, NeLH guidelines findere UpToDate) entre 01-01-1999 e 25-08-2007, em língua inglesa, portuguesa e espanhola, com as palavras-chave «prenatal diagnosis» $\mathrm{e}$ «Down syndrome», e no site IndexRMP com a palavra-chave «rastreio pré-natal».
Foram definidos os seguintes critérios de inclusão: 1) população: mulheres com gravidezes espontâneas unifetais; 2) intervenção: qualquer método de rastreio pré-natal de cromossomopatias e defeitos do tubo neural; 3) outcome: eficácia (maior taxa de detecção) e segurança (menor percentagem de falsos positivos) dos 
métodos de rastreio; 4) estudos: meta-análises, revisões sistemáticas, ensaios aleatorizados controlados, ensaios controlados, estudos prospectivos, revisões baseadas na evidência, guidelines (recomendações) e guidelines baseadas na evidência.

Na pesquisa inicial obteve-se um total de 475 artigos. A selecção inicial, baseada na leitura dos resumos dos trabalhos, permitiu a exclusão de artigos repetidos ou que não respeitassem os critérios de inclusão; foram assim obtidos 25 artigos para leitura. Destes, foram seleccionados, de acordo com os critérios de inclusão, 17 artigos: 2 guidelines, ${ }^{14,19} 1$ guideline baseada na evidência, ${ }^{20} 2$ revisões baseadas na evidência, ${ }^{15,18} 3$ revisões sistemáticas ${ }^{21-23}$ e 9 estudos prospectivos. ${ }^{24-32}$

Os resultados obtidos foram classificados por níveis de evidência segundo a taxonomia da American Family Physician (Strength of Recommendation Taxonomy SORT). ${ }^{33}$

\section{RESULTADOS}

No contexto de gravidezes espontâneas unifetais o RPN deverá ser proposto em todos os casos?

Dos artigos selecionados, apenas três se referem a esta questão. Um deles é uma recomendação baseada na evidência de 2003 encomendada pelo National Institute for Clinical Excellence (NICE) e elaborada pelo National Collaborating Centre for Women's and Children's Health (NCC-WCH), que recomenda a proposta do RPN às mulheres grávidas, sem especificar idades. ${ }^{20}$

As recomendações de consenso de 2007 da Society of Obstetricians and Gynaecologists of Canada (SCOG) recomendam que se proponha a todas as mulheres do Canadá, independentemente da idade, e através de consentimento informado, um teste de RPN para as aneuploidias clinicamente mais significativas juntamente com uma ecografia no $2^{\circ}$ trimestre para datar e avaliar o crescimento e anomalias fetais. Segundo estas recomendações, a idade materna é um fraco pré-requisito para a realização de RPN e deve ser excluído como indicação para RPN. A amniocentese/biopsia das vilosidades coriónicas não deve ser realizada sem a presença dos resultados do RPN, excepto para as mulheres com idade igual ou superior a 40 anos na data do parto, as quais poderão optar por avançar de imediato para um teste de DPN [SORT B].$^{19}$

Segundo as recomendações de consenso de 2007 do
American College of Obstetricians and Gynecologists (ACOG) e da Society for Maternal-Fetal Medicine, o RPN e o DPN devem estar disponíveis para todas as mulheres que iniciem a sua rotina pré-natal antes das 20 semanas de gestação, independentemente da sua idade. As mulheres deverão ser aconselhadas tendo em conta as características e as diferenças entre o RPN e o DPN [SORT C]. A idade materna de 35 anos não deverá ser, por si só, utilizada como limite para derminar a quem é proposto o RPN ou o DPN [SORT C]. ${ }^{14}$

\section{Qual o método de rastreio mais eficaz e mais seguro?}

Relativamente a esta questão, as três recomendações seleccionadas estabelecem standards mínimos que os testes de RPN propostos às grávidas devem cumprir. A ACOG recomenda que se proponha métodos de RPN com taxas de detecção elevadas [maior eficácia] e com baixa taxa de falsos positivos [maior segurança, pois evita a realização desnecessária de amniocentese], sem definir valores mínimos..$^{14}$ A SCOG recomenda que, em 2007, qualquer método de RPN proposto às mulheres canadenses tenha uma taxa de detecção de pelo menos $75 \%$ e uma taxa de falsos positivos não superior a $5 \%$ [SORT C].${ }^{19}$ As recomendações da NCC-WCH vão no sentido de se oferecer o RPN às mulheres grávidas com um método que apresente uma taxa de detecção superior a $60 \%$ e uma taxa de falsos positivos inferior a $5 \%$. Em Abril de 2007 esses valores deverão ser 75\% e 3\%, respectivamente. ${ }^{20}$

Os estudos originais seleccionados através da metodologia descrita estão representados no Quadro II, onde estão discriminadas as taxas de detecção e de falsos positivos (proporção de mulheres não afectadas com resultado positivo) dos vários métodos estudados. Por vezes os autores apresentam dois resultados diferentes por método, de acordo com o valor de falsos positivos adoptado. Veja-se por exemplo o estudo de Malone $e t$ $a l, 2005$ (primeira linha do Quadro II), em que, relativamente ao rastreio do $1^{\circ}$ trimestre combinado, a taxa de detecção é de $87 \%$ para uma taxa de $5 \%$ de falsos positivos ou de $73 \%$ se se adoptar uma taxa de falsos positivos de $1 \%$. Note-se que não é possível comparar directamente os valores entre diferentes estudos porque muitas vezes eles são baseados em diferentes limites para «rastreio positivo» (risco aumentado). Apesar disso, vários dos métodos existentes cumprem os stan- 


\begin{tabular}{|c|c|c|c|c|c|c|c|c|c|c|}
\hline & 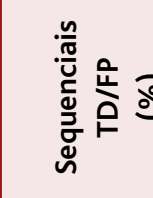 & 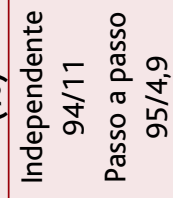 & 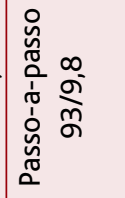 & 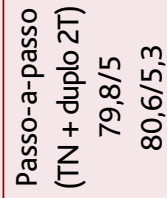 & 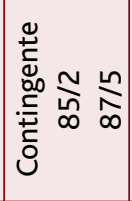 & 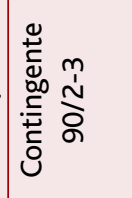 & 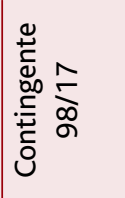 & & & \\
\hline 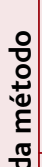 & 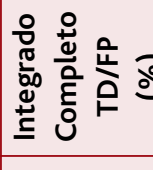 & $\sum_{\substack{n \\
\varnothing}} \underset{\infty}{\infty}$ & 迄 & & & & & & & \\
\hline & 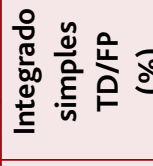 & $\ln _{\infty}^{n} \frac{\Gamma}{m}$ & $\underset{\infty}{\ln } \underset{\infty}{\stackrel{m}{r}}$ & & & & & & & \\
\hline 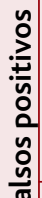 & $\frac{0}{\frac{0}{2}}$ & $\sum_{\infty}^{n} \delta$ & ${\underset{\infty}{\infty}}_{\infty}^{n} \bar{\zeta}$ & & & & & & & \\
\hline $\begin{array}{l}\frac{\pi}{4} \\
\frac{8}{0}\end{array}$ & 은 는 品 & ำร & $\underset{i}{i} \bar{\delta}$ & & & & & & & \\
\hline 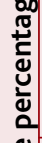 & 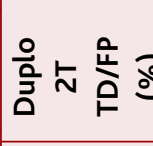 & & & $\mid \begin{array}{l}\infty \\
N^{-} \\
\infty \\
\infty \\
0 \\
0\end{array}$ & & & & & & \\
\hline$\stackrel{0}{\mathrm{a}}$ & 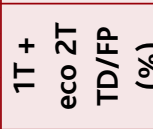 & & & & & & & & & \begin{tabular}{l}
\multirow{N}{*}{} \\
$\stackrel{5}{N}$ \\
$\infty$ \\
$\infty$
\end{tabular} \\
\hline 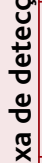 & 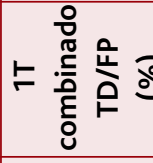 & $\frac{n}{\infty} \frac{\infty}{m}$ & $\ln _{\infty} \underset{\infty}{\grave{N}}$ & 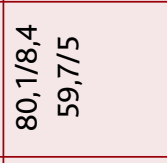 & 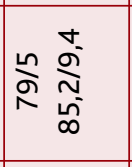 & 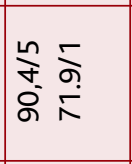 & & 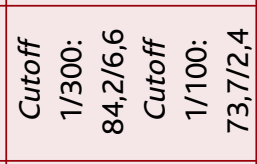 & 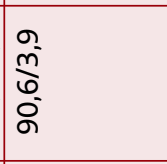 & $\begin{array}{l}\hat{n} \\
\frac{\hat{n}}{2} \\
\end{array}$ \\
\hline డ & 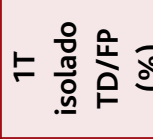 & $\stackrel{n}{\Omega}$ & & & 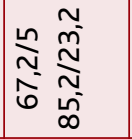 & & & & & \\
\hline & $z$ 능 & $\stackrel{\text { }}{\curvearrowright}$ & 艺 & 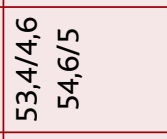 & & & & 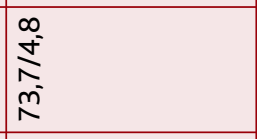 & & \\
\hline & 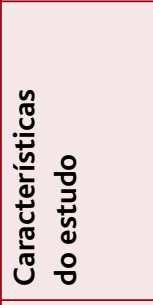 & 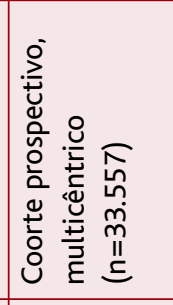 & 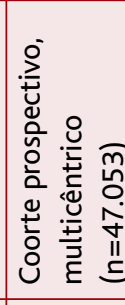 & 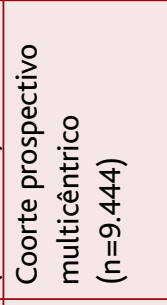 & 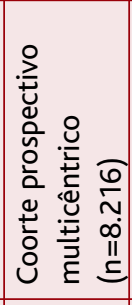 & 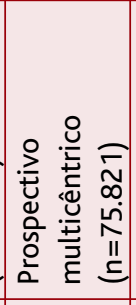 & 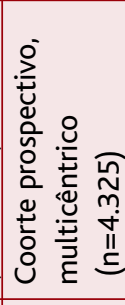 & 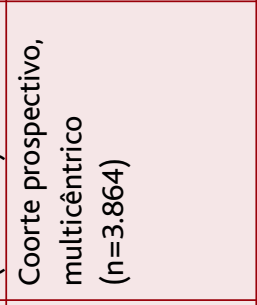 & 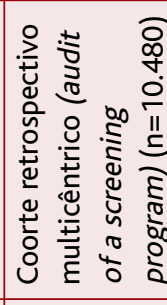 & 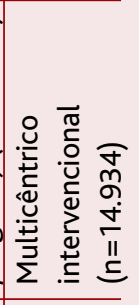 \\
\hline & & 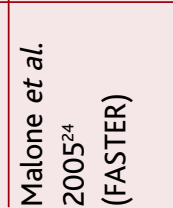 & 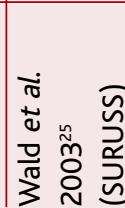 & 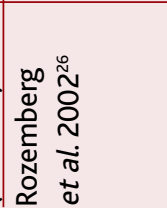 & 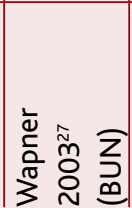 & 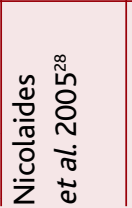 & 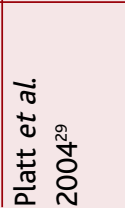 & 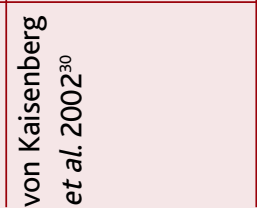 & 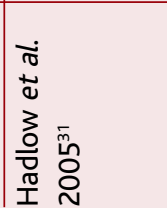 & 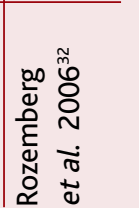 \\
\hline
\end{tabular}


dards estabelecidos nas recomendações.

Uma revisão sistemática da New Zealand Health Technology Assessment (NZHTA) incluiu todos os estudos representados no Quadro II, à excepção do estudo de Rozemberg et al. 2006. ${ }^{21}$ A revisão sistemática incluiu 35 estudos originais sobre a validade das estratégias de RPN, tendo chegado às seguintes conclusões: 1) a idade materna isolada não é um método de rastreio adequado; 2) os métodos de RPN que combinam os testes de forma independente não são recomendados; 3) o rastreio quádruplo do $2^{\circ}$ trimestre apresenta a melhor eficácia entre os testes do $2^{\circ}$ trimestre; 4 ) o rastreio do $1^{\circ}$ trimestre combinado é superior aos restantes rastreios do $1^{\circ}$ trimestre e aos do $2^{\circ}$ trimestre; 5) o rastreio integrado simples apresenta uma eficácia semelhante ao rastreio combinado; 6 ) todas as outras estratégias integradas e sequenciais têm eficácia superior aos métodos do $1^{\circ}$ e $2^{\circ}$ trimestres; 7 ) o rastreio integrado é superior aos rastreios sequenciais passo-a-passo e contingente, com uma taxa de falsos positivos inferior para uma taxa de detecção fixa; 8) a eficácia dos rastreios sequenciais passo-a-passo e contingente é semelhante. Em resumo: rastreio integrado completo $>$ sequenciais (passo a passo $\sim$ contingente) $>1^{\circ}$ trimestre combinado $\sim$ integrado simples $>$ quádruplo $2^{\circ}$ trimestre $>$ restantes métodos do $1^{\circ} \mathrm{e} 2^{\circ}$ trimestres. ${ }^{21}$

Outra das revisões sistemáticas seleccionadas, elaborada em 2003 pelo australiano Medical Services Advisory Committee (MSAC), incluiu 138 artigos e seguiu uma metodologia definida pela Cochrane Collaboration. Este trabalho analisou a eficácia e custo-eficácia dos rastreios do $1^{\circ}$ trimestre (medição isolada da $\mathrm{TN}$, rastreio do $1^{\circ}$ trimestre isolado e combinado) e do $2^{\circ}$ trimestre (duplo, triplo, quádruplo), tendo concluído que a medição isolada da $\mathrm{TN}$ e o rastreio do $1^{\circ}$ trimestre combinado são seguros e eficazes quando realizados por profissionais com treino apropriado em medição ecográfica da TN. ${ }^{22}$

A terceira revisão sistemática seleccionada, elaborada em 2002 pela Malasian Health Technology Assessment Unit (MHTAU), teve como objectivo a avaliação da eficácia, segurança, custo-eficácia e implicações éticas, legais e sociais do rastreio do SD, DTN (comparou apenas os rastreios do $1^{\circ}$ trimestre e o triplo do $2^{\circ}$ trimestre + / - ecografia para datar a gravidez) e talassemia. Relativamente ao SD, a MHTAU conclui que exis- te evidência suficiente para apoiar a utilização de marcadores séricos triplos no $2^{\circ}$ trimestre (AFP, $\mu$ E3, $\beta$-hCG) combinados com ecografia para datar a gravidez. No entanto, devido aos vários problemas éticos e religiosos que envolvem o RPN numa sociedade maioritariamente muçulmana como a da Malásia, a MHTAU não recomenda a criação de um programa nacional com realização do RPN por rotina. ${ }^{23}$

As duas revisões baseadas na evidência seleccionadas foram elaboradas por uma equipa de autores de alguns trabalhos de investigação nesta área e publicadas/actualizadas no site Uptodate no início de 2007. Estes dois trabalhos apresentam recomendações úteis para a escolha do método de RPN mais apropriado: 1) a escolha do teste depende dos objectivos da doente, da idade gestacional com que a grávida inicia a vigilância pré-natal, dos custos dos testes e da disponibilidade de recursos na comunidade; 2) quando a grávida inicia a vigilância pré-natal antes das 14 semanas completas de gestação, o método mais eficaz e com menos falsos positivos é o rastreio integrado completo;3) quando não está disponível a medição ecográfica da TN, o melhor método é o integrado simples; 4) quando a grávida se apresenta no $1^{\circ}$ trimestre mas não quer aguardar pelos resultados do $2^{\circ}$ trimestre, há 2 opções: os rastreios sequenciais (passo-a-passo ou contingente), ou o rastreio do $1^{\circ}$ trimestre combinado; 5) para as mulheres que iniciam a vigilância pré-natal após as 14 semanas completas, o rastreio quádruplo do $2^{\circ}$ trimestre é o mais adequado. Quando é realizado o rastreio do $1^{\circ}$ trimestre combinado, é aconselhável o rastreio de DTN no $2^{\circ}$ trimestre através da quantificação de alfa-fetoproteína ou ecografia. O rastreio sequencial independente é desaconselhado. ${ }^{15,18}$

As recomendações da ACOG apresentam recomendações para a prática clínica semelhantes às apresentadas no Uptodate, com alguns acréscimos. Relativamente à escolha entre o rastreio integrado completo $\mathrm{e}$ os rastreios sequenciais passo-a-passo e contingente, uma das vantagens é a mulher saber logo dos resultados do $1^{\circ}$ trimestre. No entanto, para as mulheres que preferem tomar decisões o mais precocemente possível com base num teste diagnóstico, só se houver possibilidade para a realização de uma biopsia das vilosidades coriónicas (exame recomendado no $1^{\circ}$ trimestre) é que os rastreios sequenciais são vantajosos. ${ }^{14}$ 


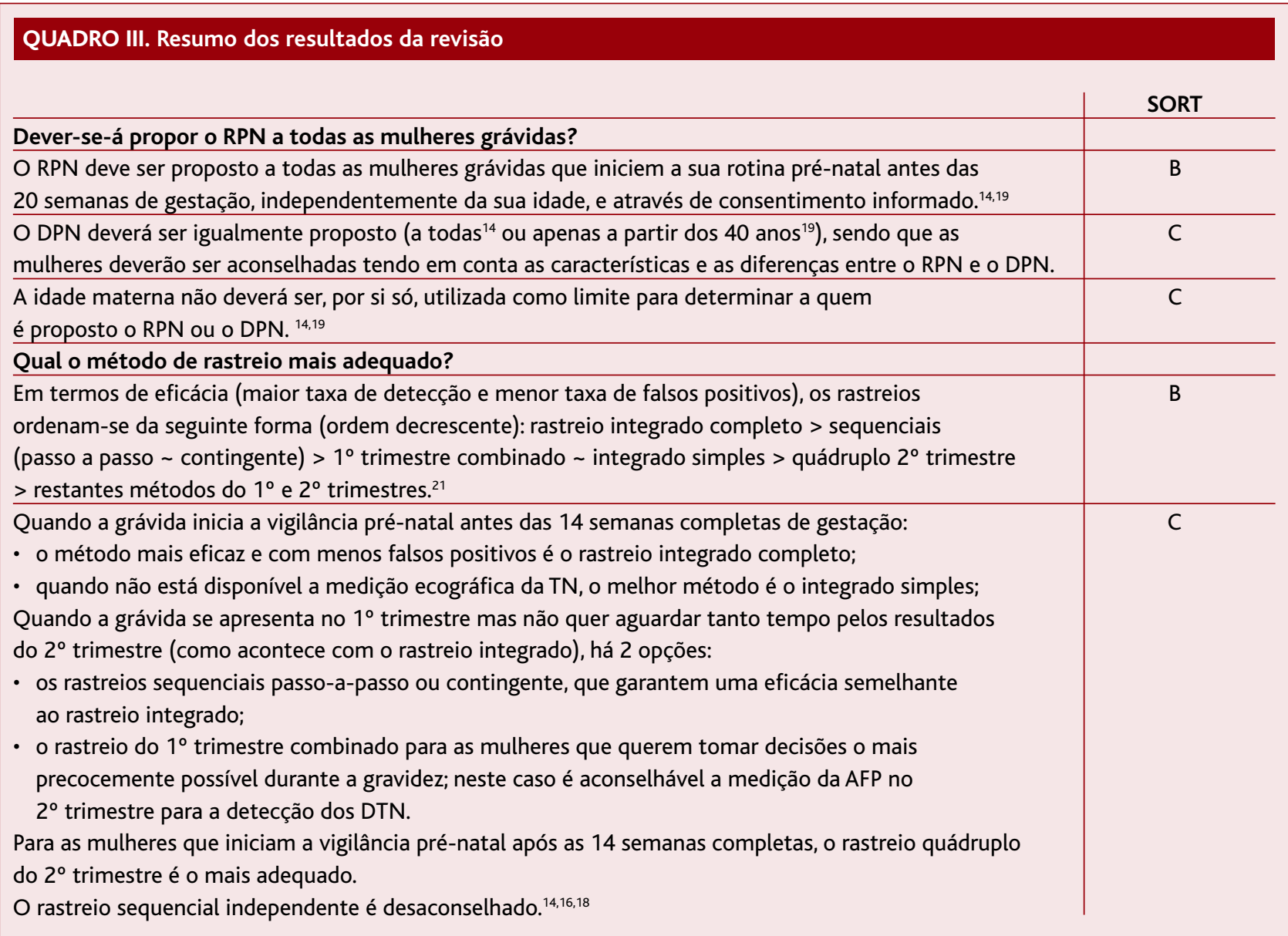

Em Portugal, a biopsia das vilosidades coriónicas é praticamente inexistente. A amniocentese é realizada entre as 15 e as 17 semanas de gestação. Tecnicamente, é possível realizar uma amniocentese a partir das 11 semanas, no entanto a amniocentese precoce não é recomendada devido ao elevado risco de morte fetal e anomalias congénitas como o pé boto. ${ }^{34}$

A ACOG recomenda que, nos casos em que é detectada uma translucência da nuca igual ou superior a $3,5 \mathrm{~mm}$, apesar de um RPN negativo ou cromossomas fetais normais, seja proposta a realização de uma ecografia dirigida e/ou um ecocardiograma fetal. ${ }^{14}$

O Quadro III apresenta os resultados da presente revisão, classificados por níveis de evidência segundo a taxonomia da American Family Physician.

\section{CONCLUSÕES}

A evidência actual permite responder a questões que poderão ajudar a orientar os médicos na sua prática clínica diária relativamente ao RPN. No entanto, as recomendações que resultam dessa evidência (classificadas nesta revisão com SORT B e C) não apresentam força suficiente para que possam ser tomadas decisões com a máxima segurança. Acresce que os trabalhos que fundamentam esta revisão são baseados em realidades diferentes da portuguesa.

Em Portugal existem poucos trabalhos publicados sobre RPN. Um trabalho de revisão publicado em 2003 na Revista Portuguesa de Clínica Geral ${ }^{35}$ descreve os métodos existentes (não fazendo nenhuma comparação entre eles), o cálculo do risco e a interpretação dos 
resultados dos testes. Relativamente à primeira questão desta revisão, afirma (baseado no livro Medicina Materno-Fetal ${ }^{36}$ que o RPN deve ser aplicado a grávidas com menos de 35 anos e sem antecedentes de DTN ou cromossomopatias, e refere as recomendações do American College of Obstetritians and Gynecologists que vão no sentido de propor o RPN às grávidas com idade superior a 35 anos que recusem a amniocentese.

Relativamente à custo-eficácia dos diferentes métodos de rastreio, é difícil extrapolar conclusões de estudos estrangeiros para a realidade portuguesa. $\mathrm{O}$ custo e a comparticipação dos diferentes testes, por exemplo, pode ser diferente. Um estudo português de custo-eficácia, publicado em 2004, teve como objectivo comparar os custos e viabilidade de dois métodos de rastreio bioquímico/ecográfico ( $1^{\circ}$ trimestre: TN e PAPP-A; $2^{\circ}$ trimestre: AFP, estriol não conjugado, beta-HCG) com o rastreio por idade materna, e avaliar retrospectivamente quais os resultados que teriam sido obtidos se fossem combinados marcadores de dois períodos da gestação para produzir um único risco integrado. Chegou-se à conclusão que «a aplicação de qualquer dos três esquemas de rastreio estudados em comparação com o rastreio pela idade materna permitiria detectar pelo menos o mesmo número de casos de SD reduzindo de três a cinco vezes o número de amniocenteses realizadas». No entanto, não estabelece diferenças entre os métodos de RPN estudados. ${ }^{37}$

Actualmente em Portugal são realizados vários métodos de RPN ( $1^{\circ} \mathrm{T}, 2^{\circ} \mathrm{T}$ e integrados), diferentes de centro para centro. Os rastreios sequenciais não são realizados pelo facto de praticamente não haver disponibilidade de DPN no $1^{\circ}$ trimestre (biopsia das vilosidades coriónicas).

O rastreio pré-natal de cromossomopatias levanta várias questões éticas com que as grávidas, os casais, os profissionais de saúde e as autoridades públicas têm que lidar. O RPN não oferece uma opção terapêutica para as cromossomopatias. A única medida preventiva possível é a interrupção da gravidez. Isto coloca os casais perante decisões difíceis, logo no início da gravidez, decisões essas que têm que ser tomadas rapidamente. ${ }^{38}$ É importante, por isso, que o primeiro passo de qualquer método de rastreio seja o fornecimento de informação objectiva e isenta sobre os benefícios, limitações e consequências dos testes, para que os casais pos-
QUADRO IV. Informação a fornecer à grávida antes

de requisitar o teste de rastreio

- Os testes de RPN rastreiam apenas Trissomia 21, Trissomia 18 e DTN. Fornecer à grávida informação resumida sobre estas patologias.

- A probabilidade de ter um «rastreio positivo» para Trissomia 21 ou Trissomia 18 aumenta com a idade informação especialmente importante para grávidas com mais de 35 anos (diminui a ansiedade se receberem a notícia de um rastreio positivo);

- Um teste de rastreio não dá a certeza de que o bebé está afectado por uma destas patologias. O «rastreio positivo» significa que existe um risco elevado; o «rastreio negativo» significa que o risco é baixo.

- $5 \%$ ( $1 \%$ se rastreio integrado completo) das mulheres rastreadas terá um «rastreio positivo» (risco aumentado) sem ter o bebé afectado («falsos positivos»).

- Perante um resultado «rastreio positivo», será proposto um exame de diagnóstico [amniocentese e/ou ecografia morfológica]. A amniocentese está associada a um risco de aborto de $1 \%$.

- O teste de rastreio não detecta todas as gestações afectadas com Trissomia 21, Trissomia 18 ou DTN. Um «rastreio negativo» não quer dizer que o bebé não terá nenhuma anomalia!

- Nos raros casos em que a ecografia/amniocentese realizada na sequência de um rastreio positivo fizer o diagnóstico de anomalia fetal, existem duas opções:

- Interrupção da gravidez (legalmente aceite até às 24 semanas de gestação).

- Continuação da gravidez e preparação para o nascimento de uma criança com necessidades especiais (existem instituições de apoio).

- A grávida tem o direito de recusar fazer os testes em qualquer etapa do processo.

sam tomar decisões verdadeiramente esclarecidas e autónomas. ${ }^{18,20,35} \mathrm{Tal}$ informação deve incluir: 1) uma explicação breve sobre as patologias a rastrear; 2) as características dos testes oferecidos e 3) as implicações de fazer os testes: opções disponíveis após um rastreio positivo (risco aumentado), o risco de aborto iatrogénico com a amniocentese, opções disponíveis após o diagnóstico de uma anomalia fetal (interrupção da gravidez, continuação da gravidez e preparação para o nascimento de uma criança com necessidades especiais). ${ }^{39}$ 
É importante informar a grávida do seu direito de recusar fazer os testes em qualquer fase do processo. ${ }^{20} \mathrm{O}$ Quadro IV resume os pontos principais a abordar com a grávida antes de requisitar o teste de rastreio. $\mathrm{O}$ fornecimento de informação escrita é útil para garantir que os pais têm um bom entendimento das questões abordadas. ${ }^{20}$

Outras questões éticas têm sido abordadas: 1) o acesso universal ao rastreio poderá resultar na sua aplicação sistemática a todas as mulheres, violando assim o princípio da autonomia; desta forma, o RPN perderia o objectivo de fornecer aos casais uma escolha informada e tornar-se-ia uma prática eugénica; ${ }^{38,40} 2$ ) no caso do SD, o DPN não fornece qualquer informação sobre a gravidade do caso (grau de atraso mental, malformações orgânicas associadas), o que levanta questões sobre a selecção dos nascituros; ${ }^{38} 3$ ) a identificação de fetos com patologias congénitas e o consequente abortamento poderá reforçar os preconceitos contra os indivíduos com deficiência e incutir (aos próprios, aos seus familiares e à comunidade) a percepção de que eles representam um fardo para as sociedades; o RPN não deverá resultar em desvios de recursos ou diminuição dos serviços disponíveis para apoiar as pessoas com deficiência e seus familiares. ${ }^{38}$

Perante a evidência disponível sobre o RPN e as questões éticas que este recurso levanta, o papel do médico é ajudar os casais a tomar uma decisão esclarecida, fornecendo informação objectiva e isenta e escolhendo as alternativas mais eficazes e seguras, adequadas a cada caso.

\section{REFERÊNCIAS BIBLIOGRÁFICAS}

1. National Institutes of Health. Antenatal Diagnosis. NIH Consensus Statement Online 1979 Mar 5-7. Disponível em: http://consensus.nih.gov/ 1979/1979AntenatalDx012html.htm [acedido em 01/06/2009].

2. Direcção Geral da Saúde; Divisão de Saúde Materna e Planeamento Familiar. Orientações Técnicas n 2 - Vigilância pré-natal e revisão do puerpério. Lisboa: Direcção Geral de Saúde; 1993.

3. Morris JK, Mutton DE, Alberman E. Revised estimates of the maternal age specific live birth prevalence of Down's syndrome. J Med Screen 2002; 9 (1): 2-6.

4. Harris RA, Washington AE, Nease RF Jr, Kuppermann M. Cost utility of prenatal diagnosis and the risk-based threshold. Lancet 2004 Jan 24; 363 (9405): 276-82.

5. Royal College of Obstetricians and Gynaecologists. Amniocentesis and chorionic villus sampling (Guideline; no. 8). London: Royal College of Obstetricians and Gynaecologists; 2005. Disponível em:
http://www.rcog.org.uk/files/rcog-corp/uploaded-files/GT8AminiocentesisChorionicVillus2005.pdf [acedido em 01/06/2009].

6. Berkowitz RL, Roberts J, Minkoff $\mathrm{H}$. Challenging the strategy of maternal age-based prenatal genetic counseling. JAMA 2006 Mar 22; 295 (12): 1446-8.

7. Resta RG. Changing demographics of advanced maternal age (AMA) and the impact on the predicted incidence of Down syndrome in the United States: implications for prenatal screening and genetic counselling. Am J Med Genet A 2005 Feb 15; 133A (1): 31-6.

8. Adams MM, Erickson JD, Layde PM, Oakley GP. Down's syndrome: Recent trends in the United States. JAMA 1981 Aug 14; 246 (7): 758-60.

9. Merkatz IR, Nitowsky HM, Macri JN, Johnson WE. An association between low maternal serum alpha-fetoprotein and fetal chromosomal abnormalities. Am J Obstet Gynecol 1984 Apr 1; 148 (7): 886-94.

10. Taipale P, Hiilesmaa V, Salonen R, Ylöstalo P. Increased nuchal translucency as a marker for fetal chromosomal defects. N Engl J Med 1997 Dec 4; 337 (23): 1654-8.

11. Benacerraf BR. Sonographic findings associated with fetal aneuploidy. In: Basow DS, editor. UpToDate. Waltham, MA: UpToDate, 2008.

12. Nicolaides KH. The 11-13+6 weeks scan. London: Fetal Medicine Foundation; 2004

13. Cicero S, Curcio P, Papageorghiou A, Sonek J, Nicolaides K. Absence of nasal bone in fetuses with trisomy 21 at 11-14 weeks of gestation. Lancet 2001 Nov 17; 358 (9294): 1665-7.

14. American College of Obstetricians and Gynecologists Committee on Practice Bulletins. ACOG Practice Bulletin no. 77: Screening for fetal chromosomal abnormalities. Obstet Gynecol 2007 Jan; 109 (1): 217$-27$.

15. Canick JA, Messerlian GM, Farina A. First trimester and integrated screening tests for Down syndrome and trisomy 18. In: Basow DS, editor. UpToDate. Waltham, MA: UpToDate, 2008.

16. Canick JA, Messerlian GM, Farina A. Second trimester maternal serum screening fpor down syndrome. In: Basow DS, editor. UpToDate. Waltham, MA: UpToDate, 2008.

17. Canick JA. New choices in prenatal screening for Down syndrome. OBG Management Dez 2005; 17 (12):38-47- Disponível em: http://www. obgmanagement.com/pdf/1712/1712OBGM_Article1.pdf [acedido em 05/06/2097].

18. Barss VA, Messerlian GM, Canick JA. Overview of prenatal screening and diagnosis of Down syndrome. In: Basow DS, editor. UpToDate. Waltham, MA: UpToDate, 2008.

19. Summers AM, Langlois S, Wyatt P, Wilson RD; Society of Obstetrians and Gynecologists of Canada. Prenatal screening for fetal aneuploidy. J Obstet Gynaecol Can 2007 Feb; 29 (2): 146-79.

20. National Collaborating Centre for Women's and Children's Health, commissioned by the National Institute for Clinical Excellence. Antenatal care: routine care for the healthy pregnant woman. London: RCOC Press; 2003.

21. O'Connell R, Stephenson M, Weir R. Screening strategies for antenatal Down syndrome Screening: a systematic review of the literature. Christchurch: New Zealand Health Technology Assessment (NZHTA); 2006. Disponível em: http://nzhta.chmeds.ac.nz/publications/downs.pdf [acedido em 04/05/2009].

22. Medical Services Advisory Committee (MSAC). Nuchal translucency 
measurement in the first trimester of pregnancy for screening of trisomy 21 and other autosomal trisomies. Canberra: MSAC; 2003.

23. Malaysian Health Technology Assessment Unit. Maternal screening for foetal abnormality. Malasia: Malaysian Health Technology Assessment Unit (MHTAU); 2002. Disponível em: www.moh.gov.my/MohPortal/DownloadServlet?id=739\&type=2 [acedido em 04/05/2009].

24. Malone FD, Canick JA, Ball RH, Nyberg DA, Comstock CH, Bukowski R, et al. First-trimester or second-trimester screening, or both, for Down's syndrome. N Engl J Med 2005 Nov 10; 353 (19): 2001-11.

25. Wald NJ, Rodeck C, Hackshaw AK, Walters J, Chitty L, Mackinson AM; SURUSS Research Group. First and second trimester antenatal screening for Down's syndrome: the results of the Serum, Urine and Ultrasound Screening Study (SURUSS). Health Technol Assess 2003; 7(11): 1-77.

26. Rozenberg P, Malagrida L, Cuckle H, Durand-Zaleski I, Nisand I, Audibert $F$, et al. Down's syndrome screening with nuchal translucency at $12(+0)-14(+0)$ weeks and maternal serum markers at 14(+1)-17(+0) weeks: a prospective study. Hum Reprod 2002 Apr; 17 (4): 1093-8.

27. Wapner RJ. First trimester screening: the BUN study. Semin Perinatol 2005 Aug; 29 (4): 236-9.

28. Nicolaides KH, Spencer K, Avgidou K, Faiola S, Falcon O. Multicenter study of first-trimester screening for trisomy 21 in 75821 pregnancies: results and estimation of the potential impact of individual risk-orientated two-stage first-trimester screening. Ultrasound Obstet Gynecol 2005 Mar; 25 (3): 221-6.

29. Platt LD, Greene N, Johnson A, Zachary J, Thom E, Krantz D, et al; First Trimester Maternal Serum Biochemistry and Fetal Nuchal Translucency Screening (BUN) Study Group. Sequential pathways of testing after first-trimester screening for trisomy 21. Obstet Gynecol 2004 Oct; 104 (4): 661-6.

30. von Kaisenberg CS, Gasiorek-Wiens A, Bielicki M, Bahlmann F, Meyberg $\mathrm{H}$, Kossakiewicz A, et al; German Speaking Down Syndrome Screening Group. Screening for trisomy 21 by maternal age, fetal nuchal translucency and maternal serum biochemistry at 11-14 weeks: a German multicenter study. J Matern Fetal Neonatal Med 2002 Aug; 12 (2): 89$-94$.

31. Hadlow NC, Hewitt BG, Dickinson JE, Jacoby P, Bower C. Communitybased screening for Down's Syndrome in the first trimester using ultrasound and maternal serum biochemistry. BJOG 2005 Nov; 112 (11): 1561-4.
32. Rozenberg P, Bussières L, Chevret S, Bernard JP, Malagrida L, Cuckle H, et al. Screening for Down syndrome using first-trimester combined screening followed by second-trimester ultrasound examination in an unselected population. Am J Obstet Gynecol 2006 Nov; 195 (5): 1379$-87$.

33. Ebell MH, Siwek J, Weiss BD, Woolf SH, Susman J, Ewigman B, et al. Strength of Recommendation Taxonomy (SORT): a patient-centered approach to grading evidence in the medical literature. Am Fam Physician 2004 Feb 1; 69 (3): 548-56.

34. Ghidini A. Amniocentesis: technique and complications. In: Basow DS, editor. UpToDate. Waltham, MA: UpToDate, 2008.

35. Ferreira M. Rastreio pré-natal. Rev Port Clin Geral 2003 Set-Out; 19 (5): 443-6.

36. Graça LM. Medicina Materno Fetal 1. $2^{\text {a }}$ ed. Lisboa: Lidel; 2000.

37. Cunha AC, Justiça MA, Rodrigues MC, Ramos C, Valente E, Monteiro J, et al. Avaliação da relação custo-benefício do rastreio de cromossomopatias no $1^{\circ}$ e $2^{\circ}$ trimestres da gestação através de marcadores ecográficos e bioquímicos versus rastreio por idade materna. Rev Obstetr Ginecol 2004; 27 (1): 31-44.

38. Agence d'Évaluation des Technologies et des Modes d'Intervention en Santé (AETMIS). First-trimester prenatal screening for Down syndrome and other aneuploidies. (AETMIS 03-01). Montréal: AETMIS; 2003. Disponível em: http://www.aetmis.gouv.qc.ca/site/download.php?f= 6fab995deb5d3bc976785baa51021405 [acedido em 04/05/2009].

39. Marteau TM, Dormandy E. Facilitating informed choice in prenatal testing: how well are we doing? Am J Med Genet 2001 Fall; 106 (3): 185$-90$.

40. Reynolds TM. Down's syndrome screening is unethical: views of today's research ethics comitees. J Clin Pathol 2003 Apr; 56 (4): 268-70.

Conflitos de Interesse: não assinalados

\section{ENDEREÇO PARA CORRESPONDÊNCIA}

Sílvia Henriques

Rua Gonçalo Mendes da Maia, $378,3^{\circ}$ dto - traseiras

4425-656 Pedrouços

Tlm: 966464460

E-mail: silviahenriq@gmail.com 


\section{ABSTRACT}

Objectives: Prenatal screening (PS) offers the advantage of determining, non invasively, the risk of trisomy 21,18 and neural tube defects (NTD). There are still some doubts about its proper use. The objective of this review is to answer to the following: should PS be offered to all pregnant women? What's the best screening method?

Data Sources: Medline, Tripdatabase, Cochrane, National Guideline Clearinghouse, CMAinfobase, NeLH guidelines finder, UpToDate, IndexRMP.

Review methods: Systematic review of articles published from 01-01-1999 to 25-08-2008) in English, Portuguese and Spanish, using the keywords «prenatal diagnosis» and «Down syndrome», and «rastreio pré-natal» for the Portuguese site IndexRMP. The selection included 2 guidelines, 1 EBM guideline, 2 EBM reviews, 3 systematic reviews and 9 prospective studies. The results were classified with evidence levels according to the American Family Physician taxonomy.

Participants: Women with spontaneous unifetal pregnancies

Results: PS should be offered to all pregnant women presenting before 20 weeks of gestation, regardless of maternal age, after informed consent. Prenatal diagnosis should also be offered after proper information. Maternal age should not be used as a cutoff to offer PS or prenatal diagnosis. [C]

Before 14 weeks of gestation the most effective and safe method is the full integrated test; if nuchal translucency measurement is not available, the serum integrated test is the next best choice. For women who want an early result there are two choices: the sequential screening (stepwise or contingent) or the first trimester combined test (in this case NTD screening should be offered in the 2 nd trimester - alpha-fetoprotein measurement or ultrasound). Independent sequential screening is not recommended. [C]

Conclusions: According to the scientific evidence and ethic issues surrounding PS, doctors should help couples decide autonomously providing objective information and choosing the most effective and safe methods adapted to each specific case.

Keywords: Prenatal Screening; Down Syndrome; Trisomy 18; Neural Tube Defects. 